\title{
Early thrombosis risk in patients with biologic valves in the aortic position
}

\author{
Morgan L. Brown, MD, PhD, ${ }^{a}$ Soon J. Park, MD, ${ }^{b}$ Thoralf M. Sundt, MD, ${ }^{\mathrm{b}}$ and Hartzell V. Schaff, $\mathrm{MD}^{\mathrm{b}}$
}

Objective: Patients who require aortic valve replacement are increasingly receiving biologic valves to avoid long-term anticoagulation. The thromboembolic risk of bioprosthetic valves is reportedly low. The study objective was to review the incidence of early valve thrombosis requiring reoperation in patients who received a bioprosthetic valve in the aortic position.

\begin{abstract}
Methods: We reviewed all adult patients who had a biologic valve implanted in the aortic position at Mayo Clinic between January 1993 and July 2009. Records were reviewed for all cases of reoperation that occurred less than 2 years postoperatively. Incidences of valve thrombosis were calculated including $95 \%$ Poisson confidence intervals.

Results: During the study interval, 4568 patients received biologic valves for aortic valve replacement. We identified 8 patients who underwent reoperation to replace the aortic prosthesis because of thrombus that resulted in functional aortic stenosis. The median age of patients at the time of reoperation was 77 years (range, 52-86), and the median time to reoperation was 398 days (range, 106-626). All patients with valve thrombosis received a stented porcine valve: St Jude Biocor (St Jude Medical, Inc, St Paul, Minn) in 4 patients, Medtronic Mosaic (Medtronic Inc, Minneapolis, Minn) in 2 patients, and Medtronic Hancock (Medtronic Inc) in 2 patients. The calculated incidence of valve thrombosis was $1.26 \%$ (confidence interval, 0.56-1.96) for the Biocor valve, $0.37 \%$ (confidence interval, $0.19-0.56$ ) for the Mosaic valve, and $0.84 \%$ (confidence interval, $0.42-1.25$ ) for the Hancock valve $(P=.34)$. There were no cases of valve thrombosis in patients who received a pericardial valve (5923 patient-years) or stentless valve (172 patient-years).
\end{abstract}

Conclusions: The incidence of early thrombosis of porcine aortic bioprostheses requiring reoperation was not insignificant. Potential causes and mechanisms for such thrombosis are unknown. Recognition of this unanticipated problem and reoperation resulted in a satisfactory outcome for patients. (J Thorac Cardiovasc Surg 2012;144:108-11)

Patients who require aortic valve replacement are increasingly receiving biologic valves rather than mechanical valves to avoid long-term anticoagulation and its potential complications. ${ }^{1-3}$ Although risk of thromboembolic events after bioprosthetic aortic valve replacement is higher in the first 3 months than later, ${ }^{4,5}$ recent studies suggest that early anticoagulation in low-risk patients does not significantly decrease the incidence of thromboembolism..$^{6-8}$

In a meta-analysis based on microsimulation, Puvimanasinghe and colleagues ${ }^{9}$ estimated the linearized occurrence rate of thrombosis for an aortic valve bioprosthesis to be 0.03 events per 100 patient-years, but this estimate is based on only 3 events in 9925 patient-years of follow-up. We

From the Department of Anesthesiology and Pain Medicine, ${ }^{a}$ University of Alberta, Edmonton, Alberta, Canada; and the Division of Cardiovascular Surgery, ${ }^{\mathrm{b}}$ Mayo Clinic, Rochester, Minn.

Disclosures: Authors have nothing to disclose with regard to commercial support.

Received for publication Oct 23, 2010; revisions received Feb 20, 2011; accepted for publication May 18, 2011; available ahead of print Aug 24, 2011.

Address for reprints: Soon J. Park, MD, Division of Cardiovascular Surgery, Mayo Clinic, 200 First Street SW, Rochester, MN 55905 (E-mail: park.soon@ mayo.edu). $0022-5223 / \$ 36.00$

Copyright (c) 2012 by The American Association for Thoracic Surgery doi:10.1016/j.jtcvs.2011.05.032 recently observed several cases of symptomatic early thrombosis of bioprosthetic valves. Our objective was to review the incidence of reoperation for early valve thrombosis in patients who received a bioprosthetic valve in the aortic position.

\section{MATERIALS AND METHODS}

After institutional review board approval, we reviewed adult patients ( $>18$ years) who had a biologic valve implanted in the aortic position at Mayo Clinic (Rochester, Minn). Patient records and follow-up surveys were used to identify all cases of reoperation less than 2 years after implantation of the biologic valve. Medical records and pathology reports were reviewed for evidence of thrombosis as a mechanism of failure. Patients who had pannus, structural valve deterioration such as tears, or any evidence of infection were excluded. The incidence of thrombosis and per patient-year were calculated, along with the Poisson $95 \%$ confidence interval using StatsDirect (2007). Groups were compared using the Fisher exact test.

\section{RESULTS}

From January 1, 1993, to July 1, 2009, 4568 biologic valves were implanted in the aortic position in adult patients. Of these, 3031 were stented pericardial, 1463 were stented porcine, and 74 were stentless porcine valves.

We identified 8 patients $(0.18 \%)$ who underwent reoperation for thrombosis of a biologic aortic valve. The median 
year that the original biologic valve was implanted was 2007 (range, 1999-2007), and the median valve size was $23 \mathrm{~mm}$ (range, $21-27 \mathrm{~mm}$ ). At the time of reoperation for the thrombosed valve, the median patient age was 77 years (range, 52-86 years). The median interval between the original implant and the reoperation was 398 days (range, 106-626 days). All patients presented with symptoms, including shortness of breath, chest pain, or fatigue. No patients were hemodynamically unstable from the valve thrombosis. In all cases, echocardiography diagnosed prosthetic valve stenosis as moderate-severe or severe. Two patients also had mild aortic regurgitation.

The incidence of thrombosis was calculated for each valve type (Table 1). The St Jude Biocor (St Jude Medical, Inc, St Paul, Minn) valve had an incidence of $1.26 \%$, the Medtronic Hancock (Medtronic Inc, Minneapolis, Minn) valve had an incidence of $0.84 \%$, and the Medtronic Mosaic (Medtronic Inc) valve had an incidence of $0.37 \%$. These are all stented porcine valves. There was no difference in the incidence of thrombosis among the 3 valve types $(P=.34)$. Overall, stented porcine valves had an incidence of $0.55 \%$. There were no cases of thrombosis in stented pericardial valves or stentless porcine valves. On comparison of incidences among valve types, there was a significant difference between the stented porcine and pericardial valves $(P<.001)$. There was no statistically demonstrable difference between the stented porcine and stentless porcine valves, likely because of the small number of patients in the stentless group $(P>.05)$.

Pathology reports identified thrombus on the aortic side of the valve in all cases (Figure 1). There was minimal clot present on the ventricular side of the valves. In 1 patient, a small amount of focal calcification was present on one of the valve leaflets. There was no evidence of other causes of structural valve deterioration (eg, tears or perforation) or endocarditis in all cases. Pledgets were placed in all patients.

Patient characteristics that were postulated to be contributing factors were examined, including factors that could contribute to a change in the flow of blood past the aortic valve. The median postoperative aortic valve gradient after the original aortic valve replacement was $26 \mathrm{~mm} \mathrm{Hg}$ (range, 13-35 $\mathrm{mm} \mathrm{Hg}$ ), and the median
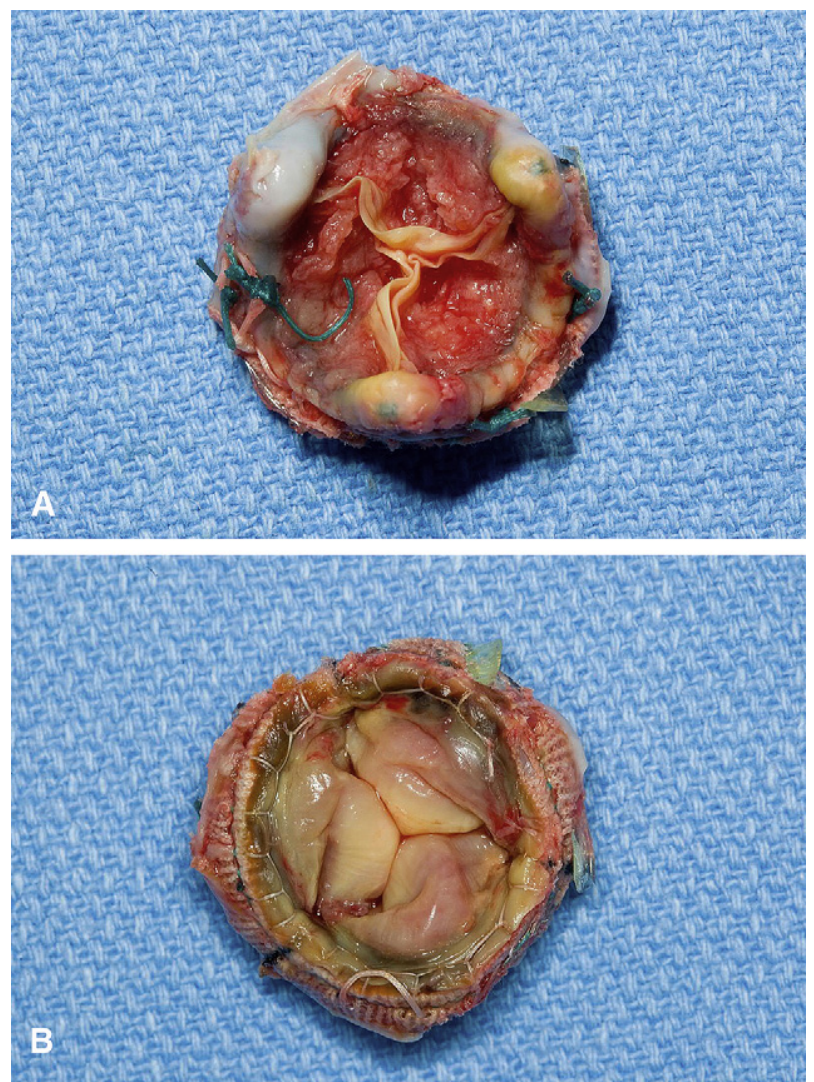

FIGURE 1. A, The aortic valve has been explanted, and there is extensive thrombus present in the cusps on the aortic side of the valve. B, The ventricular side of the valve was spared.

postoperative ejection fraction was $49 \%$ (range, $23 \%-$ $70 \%$ ). No patients had a perivalvular leak. Interval echocardiograms were not available for all patients. Valves were implanted by a number of different surgeons and surgical teams, and each implanted both porcine and pericardial prostheses. No patients showed evidence of endocarditis at any time, including positive blood cultures or fever.

All patients received aspirin therapy early after surgery and in follow-up. Only 3 of 8 patients received warfarin for the first 3 months postoperatively. On the basis of the clinical assessments and laboratory investigations

TABLE 1. Incidence of valve thrombosis

\begin{tabular}{lrccc}
\hline & N & Incidence of thrombosis & $\begin{array}{c}\text { 95\% CI of the incidence } \\
\text { of thrombosis }\end{array}$ & $\begin{array}{c}\text { Rate of thrombosis } \\
\text { (per patient year) }\end{array}$ \\
\hline Stented porcine & 1463 & $0.55 \%$ & & \\
St Jude Biocor (St Jude Medical, Inc, St Paul, Minn) & 318 & $1.26 \%$ & $0.56-1.96$ & $0.70 \%$ \\
Medtronic Mosaic (Medtronic Inc, Minneapolis, Minn) & 541 & $0.37 \%$ & $0.19-0.56$ & $0.19 \%$ \\
Medtronic Hancock (Medtronic Inc) & 270 & $0.84 \%$ & $0.42-1.25$ & 0 \\
Stented pericardial & 3031 & $0 \%$ & $0-0.3$ & 0 \\
Stentless & 74 & $0 \%$ & $0.41 \%$ \\
\hline
\end{tabular}

CI, Confidence interval. 
that were available, none of the 8 patients had an identifiable thrombophilia; however, complete workups were not available on all patients. One patient was found to have renal cell carcinoma during the workup for the valve thrombosis. No other patients were known to have active cancer or developed cancer in the 6 months after aortic valve thrombosis.

All 8 patients survived reoperation. Five patients received a mechanical valve and 3 patients received a stented pericardial valve at the time of reoperation. No patients have returned with thrombosis subsequently (median follow-up, 457 days; range, 10-3238 days).

\section{DISCUSSION}

We observed 8 reoperations secondary to valve thrombosis within 2 years of implantation of a stented porcine valve in the aortic position. The incidence of thrombosis in stented porcine valves ranged between $0.19 \%$ per patient year for the Medtronic Mosaic and $0.70 \%$ per patient year for the St Jude Biocor. No patients with pericardial valves experienced thrombosis.

The incidence of porcine prosthetic valve thrombosis reported in this article is significantly higher than that reported previously. One study estimated the incidence of valve thrombosis in porcine valves at $0.03 \%$ per patient year using a simulation model based on the available reported literature. ${ }^{9}$ There have been several case reports and small case series of early thromboses of porcine valves. ${ }^{5,10-14}$ It is difficult to assess the rate of valve thrombosis in most publications, because thromboembolism is most often reported, not valve thrombosis. Nevertheless, the event rate of early porcine valve thrombosis requiring reoperation is not clinically insignificant in our experience.

In regard to stented pericardial valves, there is one reported case of early thrombosis in a Carpentier-Edwards (Edwards Lifesciences LLC, Irvine, Calif) 19-mm pericardial valve placed in the aortic position. ${ }^{15}$ This patient died of sudden cardiac arrest on postoperative day 6 and was found to have thrombus on the aortic aspect of the prosthesis that resulted in occlusion of the valve. This patient was not taking any anticoagulation at the time and had no known risk factors for thrombosis. We did not encounter any patient with early valve thrombosis of a pericardial valve.

It is unknown whether there are risk factors specific for early valve thrombosis, because the reports are too small to make any meaningful inferences. It can be presumed that any hypercoaguable state may predispose to formation of thrombus on a foreign valve. Other contributing factors may be low ejection fraction, small valve size, or presence of perivalvular leak, early pannus, or endocarditis. All these factors may not allow for adequate washing of the valve leaflets, may cause turbulence around the valve, and may lead to thrombosis in a predisposed patient. Although we do not have direct evidence for an impact of valve design
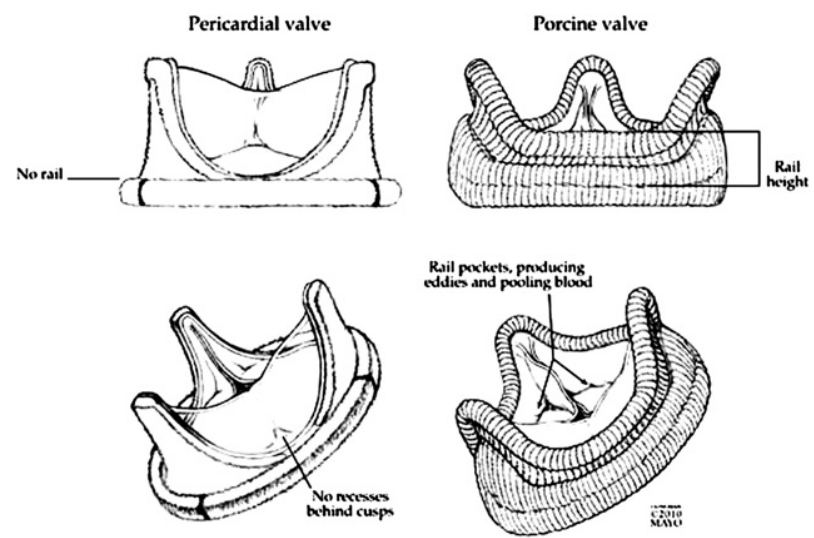

FIGURE 2. Porcine valves share a common design feature dictated by attachment of the leaflet to the stent, which is a "rail" that could promote stasis of blood in the belly of the leaflet. Pericardial valves have no rail.

on the risk of thrombosis, the porcine valves all have a design that includes a "rail" in the sinus portions (Figure 2) that could conceivably inhibit leaflet washing by creating a "bowl" around the leaflet. This could contribute to stasis and leaflet thrombosis. Thrombosis may be related to a difference in valve materials.

Whether early anticoagulation with warfarin or platelet antagonists, such as aspirin or clopidogrel, may prevent valve thrombosis is unknown. Anticoagulation in low-risk patients receiving an aortic bioprostheses did not decrease the incidence of thromboembolism in several studies. ${ }^{6-8}$ Nevertheless, it should be noted that valve thrombosis is such a rare event that it would be difficult to determine whether any therapy could be preventative and what duration of therapy would be necessary.

There are limited published data to guide the surgeon in the choice of prosthesis to be placed at the second operation after a case of porcine valve thrombosis. Because we have not had any cases of early valve thrombosis requiring reoperation in a pericardial valve implanted in the aortic position, it seems reasonable that a mechanical or pericardial valve could be used. This should be guided by the patient's preference after a full discussion of the issues.

This is an observational study and is subject to all the limitations of this study design. Valve thrombosis is defined in the literature as any thrombus not caused by infection attached to or near an operated valve that occludes part of the blood flow path, interferes with valve function, or is sufficiently large to warrant treatment. ${ }^{16}$ However, because of the study design, we cannot account for the patients who may have required treatment with anticoagulants for valve thrombosis. We did review all available follow-up information for medically treated thromboses, but we did not identify any other cases of thromboses. 


\section{CONCLUSIONS}

The incidence of early thrombosis of porcine aortic bioprostheses requiring reoperation was not insignificant. Potential causes and mechanisms for such thrombosis are unknown. Recognition of this unanticipated problem and reoperation resulted in a satisfactory outcome for patients.

\section{References}

1. Bonow RO, Carabello BA, Chatterjee K, de Leon AC Jr, Faxon DP, Freed MD, et al. 2008 focused update incorporated into the ACC/AHA 2006 guidelines for the management of patients with valvular heart disease: a report of the American College of Cardiology/American Heart Association Task Force on Practice Guidelines. J Am Coll Cardiol. 2008;52:e1-142.

2. Smedira NG, Blackstone EH, Roselli EE, Laffey CC, Cosgrove DM. Are allografts the biologic valve of choice for aortic valve replacement in nonelderly patients? Comparison of explantation for structural valve deterioration of allograft and pericardial prostheses. J Thorac Cardiovasc Surg. 2006; 131:558-64.

3. Ruel M, Chan V, Bedard P, Kulik A, Ressler L, Lam K, et al. Very longterm survival implications of heart valve replacement with tissue versus mechanical prostheses in adults $<60$ years of age. Circulation. 2007;116: I294-300.

4. Heras M, Chesebro JH, Fuster V, Penny WJ, Grill DE, Bailey KR, et al. High risk of thromboemboli early after bioprosthetic cardiac valve replacement. J Am Coll Cardiol. 1995;25:1111-9.

5. Orszulak TM, Schaff HV, Mullany CJ, Anderson BJ, Ilstrup DM, Puga FJ, et al. Risk of thromboembolism with the aortic Carpentier-Edwards bioprosthesis. Ann Thorac Surg. 1995;59:462-8.
6. ElBardissi AW, DiBardino DJ, Chen FY, Yamashita MH, Cohn LH. Is early antithrombotic therapy necessary in patients with bioprosthetic aortic valves in normal sinus rhythm? Thorac Cardiovasc Surg. 2010;139:1137-45.

7. Brueck M, Kramer W, Vogt P, Steinert N, Roth P, Gorlach G, et al. Antiplatelet therapy early after bioprosthetic aortic valve replacement is unnecessary in patients without thromboembolic risk facts. Eur J Cardiothorac Surg. 2007;32:108-12.

8. Sundt TM, Zehr KJ, Dearani JA, Daly RC, Mullany CJ, McGregor CGA, et al. Is early anticoagulation with warfarin necessary after bioprosthetic aortic valve replacement? J Thorac Cardiovasc Surg. 2005;129:1024-31.

9. Puvimanasinghe JPA, Steyerberg EW, Takkenberg JJM, Eijkemans MJC, van Herwerden LA, Bogers AJJC, et al. Prognosis after aortic valve replacement with a bioprosthesis predication based on meta-analysis and microsimulation. Circulation. 2001;103:1535-41

10. Logeais Y, Langanay T, Leguerrier A, Rioux C, Chaperon J, Coutté MB. Aortic Carpentier-Edwards supraannular porcine bioprosthesis: a 12-year experience. Ann Thorac Surg. 1999;68:421-5.

11. Edmond JJ, Greaves SC, French JK, Graham KJ, Raudkivi PJ, Blake JWH, et al Thrombotic risk in patients with aortic bioprostheses. J Heart Valve Dis. 2004; 13:525-8.

12. Baciewicz PA, del Rio C, Goncalves MA, Lattouf OM, Guyton RA, Morris DC. Catastrophic thrombosis of porcine aortic bioprostheses. Ann Thorac Surg. 1990; 50:817-9.

13. Diamant M, Jaarsma W, Morshuis WJ. Thrombolytic therapy for thrombosis of an aortic bioprosthetic valve. N Engl J Med. 1994;330:1906-7.

14. Adamick RD, Gleckel LC, Graver LM. Acute thrombosis of an aortic bioprosthetic valve: transthoracic and transesophageal echocardiographic findings. $A m$ Heart J. 1991;122:241-2.

15. Mestras C, Gardcia-Real FJ, Fuentes M. Early postoperative thrombosis of pericardial xenograft aortic valve. Asian Cardiovasc Thorac Ann. 2000;8:50-1.

16. Akins CW, Miller DC, Turina MI, Kouchoukos NT, Blackstone EH, et al. Guidelines for reporting mortality and morbidity after cardiac valve interventions. $J$ Thorac Cardiovasc Surg. 2008;135:732-8. 